\title{
Tolerância ao frio e características silviculturais do cedro-australiano no sul do Brasil
}

\author{
Marcio Carlos Navroski ${ }^{*}$, Mariane de Oliveira Pereira², Geedre Adriano Borsoi², Antonio Nascim Kalil Filho ${ }^{3}$, Bruno Nascimento ${ }^{1}$, \\ Diego Pereira da Rosa ${ }^{1}$
}

\author{
${ }^{1}$ Universidade do Estado de Santa Catarina, Av. Luiz de Camões, 2090, CEP 88520-000, Lages, SC, Brasil \\ 2Universidade Federal do Paraná, Av. Pref. Lothário Meissner, 632, CEP 80210-170, Curitiba, PR, Brasil \\ ${ }^{3}$ Embapa Florestas, Estrada da Ribeira, Km 111, C P 319, CEP 83411-000, Colombo, PR, Brasil
}

*Autor correspondente:

marcio.navroski@udesc.br

Termos para indexação:

Toona ciliata

Resistência a geada

Plantio misto

Index terms:

Toona ciliata

Frost resistance

Mixed planting

Histórico do artigo:

Recebido em 09/05/2016

Aprovado em 05/01/2017

Publicado em 31/03/2017
Resumo - O cedro australiano (Toona ciliata M. Roem) é uma espécie difundida no Sudeste, Centro-Oeste e Nordeste do Brasil, onde alcança boa produtividade. Possui madeira de excelente qualidade para finalidades nobres. Entretanto, na região Sul do Brasil apresenta problemas de adaptação devido à ocorrência de geadas. O objetivo deste estudo foi verificar a tolerância ao frio e o potencial silvicultural de cedro-australiano em dois locais no Sul do Brasil. Os tratamentos consistiram de plantio puro de cedroaustraliano e misto, com Mimosa scabrella e Eucalyptus benthamii em Lages, SC, e puro e sob Pinus taeda em Ibiam, SC. Durante dois anos após a implantação avaliou-se sobrevivência, danos por geada, bifurcação/brotação, altura total e diâmetro do colo. O cedro-australiano apresentou sérios danos pela geada no município de Lages, reduzindo drasticamente a sobrevivência e prejudicando as características silviculturais. O plantio do cedro-australiano sob pínus em Ibiam apresentou baixa taxa de mortalidade devido a geadas. O plantio puro nesta mesma região também apresentou baixa mortalidade, contudo, os efeitos das geadas foram consideráveis. O plantio de cedro-australiano não é indicado para as regiões com geadas intensas, contudo, em locais com geadas menos severas, o plantio sob pínus é uma alternativa potencial.

\section{Cold-tolerance and silvicultural features of Australian red cedar in southern Brazil}

\begin{abstract}
Australian red cedar is a widespread species in Southeast, Midwest and Northeast regions of Brazil, which achieves high productivity. It has wood of excellent quality for noble purposes. However, in Southern Brazil it presents growth adjustment problems due to frost occurrence. The aim of the study was to verify cold tolerance and silvicultural potential of Australian red cedar in two locations in Southern Brazil. Treatments consisted of pure stand of Australian red cedar, and mixed plantation with Mimosa scabrella and Eucalyptus benthamii in Lages, SC and pure stand and under Pinus taeda in Ibiam, SC. For two years after implantation survival, damage by frost, fork/budding, total height and stem diameter were evaluated. Australian red cedar showed serious damage by frost in Lages, dramatically reducing survival and damaging silvicultural characteristics. Growing Australian red cedar under P. taeda in Ibiam presented low mortality due to frost. In this location pure stand also presented low mortality, however, frost effects were considerable. Australian red cedar plantation is not suitable for areas with occurrence of heavy frosts, however, in places with less severe frosts, planting under pine is a potential alternative.
\end{abstract}




\section{Introdução}

O cedro-australiano (Toona ciliata M. Roem.) é uma árvore caducifólia, nativa desde a Índia e Malásia até o norte da Austrália, com tronco ereto e cilíndrico, revestido por casca suberosa de cor marrom (Lorenzi et al., 2003), sendo seu habitat natural as baixas e médias elevações que apresentam clima úmido (Holdridge \& Poveda, 1975). É uma espécie florestal que apresenta grande potencial para silvicultura comercial (Ares \& Fownes, 2000) e surge como uma opção ao uso de madeiras nobres nativas, como, por exemplo, o mogno (Swietenia macrophylla) e o cedro-rosa (Cedrela fissilis) (Trianoski et al., 2014).

A madeira do cedro-australiano possui coloração vermelho-clara que escurece com o tempo, brilhante, densidade média $\left(0,306 \mathrm{~g} \mathrm{~cm}^{-3}\right)$, textura moderadamente grosseira, mas uniforme, grã direita a levemente revessa e boa trabalhabilidade, durável e resistente aos cupins. Estudos apontam grande potencialidade de utilização dessa espécie de cedro em produtos de maior valor agregado, como movelaria, forros e acabamentos de construção civil (Nisgoski et al., 2011).

O cedro-australiano foi introduzido no Brasil por meio de projetos de fomento florestal realizados na região sudeste, onde encontrou condições edafoclimáticas favoráveis ao seu desenvolvimento (Pinheiro et al., 2006). Os mesmos autores colocam que a temperatura média para o desenvolvimento do cedro-australiano fica em torno de 20 a $26^{\circ} \mathrm{C}$, no entanto, a espécie sobrevive a temperaturas mínimas absolutas pouco abaixo de $0{ }^{\circ} \mathrm{C}$, podendo suportar até cinco geadas. O material genético da espécie introduzido no Brasil apresenta grande variabilidade fenotípica, o que é nitidamente observado pelas diferentes taxas de crescimento dos povoamentos implantados (Souza, 2007), mas que pode representar fonte de material genético a ser selecionado para futuros programas de melhoramento.

A variação de altitude para o plantio é alta, sendo possível o estabelecimento da cultura em baixas e elevadas altitudes, com até $1.700 \mathrm{~m}$, apesar do ritmo de crescimento ser mais lento em locais com altitudes mais acentuadas. O corte comercial do cedro-australiano ocorre aproximadamente aos 12 anos, podendo ser antecipado ou adiado, dependendo das condições específicas do povoamento e da finalidade da madeira. Sua produtividade média é de $150 \mathrm{~m}^{3} \mathrm{ha}^{-1}$ ano $^{-1}$ (avaliação aos 10 anos) após desbaste para produção de madeira serrada (Souza et al., 2010).
Uma das principais vantagens do cultivo do cedroaustraliano no Brasil é sua resistência aos ataques da broca da gema apical (Hypsipyla grandella), que causa grandes danos as Meliáceas nativas, como cedro-rosa e mogno brasileiro (Cunningham et al., 2005), e ainda não há registro de ocorrência da broca-de-ponteira (Hypsipyla robusta) em Toona ciliata nas Américas (Bygrave \& Bygrave, 2005). Outra característica relevante do cedro-australiano é a tolerância à sombra na fase jovem, ponto importante para ser observado em plantios consorciados. De maneira geral, os plantios mistos são menos suscetíveis a ataques de fungos e insetos do que as monoculturas (Bristow et al., 2005).

O crescimento da exploração comercial da cultura, comentado por Castro-Gamboa (2000), mostra a importância da geração de novos conhecimentos e estudos sobre a espécie que possibilitem o avanço tecnológico para sua produção e expansão em outras regiões do Brasil. Neste sentido, justificam-se as pesquisas que visam estudar a capacidade de tolerância a geadas e produtividade de Toona ciliata. O Sul do Brasil vem demonstrando ser historicamente uma região com grande importância para o setor florestal. Entretanto, o frio pode ser limitante para o estabelecimento de várias espécies importantes comercialmente, mesmo dentro do gênero Eucalyptus (Paludzyszyn Filho et al., 2006). Dessa forma, a introdução de espécies como o cedroaustraliano pode alavancar ainda mais o setor nessa região, principalmente em áreas com ocorrência de geadas em que muitas vezes o uso de diferentes espécies é limitado.

O objetivo desse estudo foi verificar a tolerância ao frio e o potencial silvicultural da espécie Toona ciliata em experimentos plantados em Lages e Ibiam, SC, região Sul do Brasil.

\section{Material e métodos}

O experimento foi instalado em dois locais, sendo um no Município de Lages, SC e outro em Ibiam, SC. Em Lages, o plantio foi realizado na Fazenda Experimental da Universidade do Estado de Santa Catarina, situada nas coordenas geográficas $27^{\circ} 19^{\prime} 0^{\prime}$ 'S e $50^{\circ} 19^{\prime} 35^{\prime \prime} \mathrm{W}$ e altitude de $900 \mathrm{~m}$. De acordo com a classificação de Köppen, o clima de Lages é predominantemente do tipo $\mathrm{Cfb}$, mesotérmico, subtropical úmido, com verões frescos, sem estações secas definidas e com ocorrência de geadas severas. Esse tipo climático é comum no 
Planalto Meridional Brasileiro. A temperatura média anual é de $12^{\circ} \mathrm{C}$ a $19^{\circ} \mathrm{C}$, a média mínima de $5^{\circ} \mathrm{C}$ a $8^{\circ} \mathrm{C}$, a média máxima de $22^{\circ} \mathrm{C}$ a $31^{\circ} \mathrm{C}$ e a mínima absoluta $-12^{\circ} \mathrm{C}$. A precipitação anual fica em torno de $1.300 \mathrm{~mm}$ a $2.400 \mathrm{~mm}$ (Zoneamento..., 1988).

O plantio no Município de Ibiam foi realizado em propriedade particular. O município tem como tipo de solo predominante Terra Bruna Estruturada, e clima temperado úmido, apresentando temperatura média anual de $18,5^{\circ} \mathrm{C}$ e precipitação pluviométrica em torno de 1.800 a $2.000 \mathrm{~mm}$ (Berri, 2015). A área de implantação está localizada a uma altitude média de $879 \mathrm{~m}$, coordenadas $27^{\circ} 8^{\prime} 40,00^{\prime}$ 'S e $51^{\circ} 14^{\prime} 47,47^{\prime} \mathrm{W}$.

Os dados de temperatura entre agosto de 2013 e novembro de 2015, dos municípios de Lages e Campos Novos, SC (estação meteorológica mais próxima a Ibiam) estão apresentados na Figura 1. Lages apresentou durante o período do experimento uma temperatura média de $15,6^{\circ} \mathrm{C}$, e Campos Novos temperatura média de $16,5^{\circ} \mathrm{C}$.
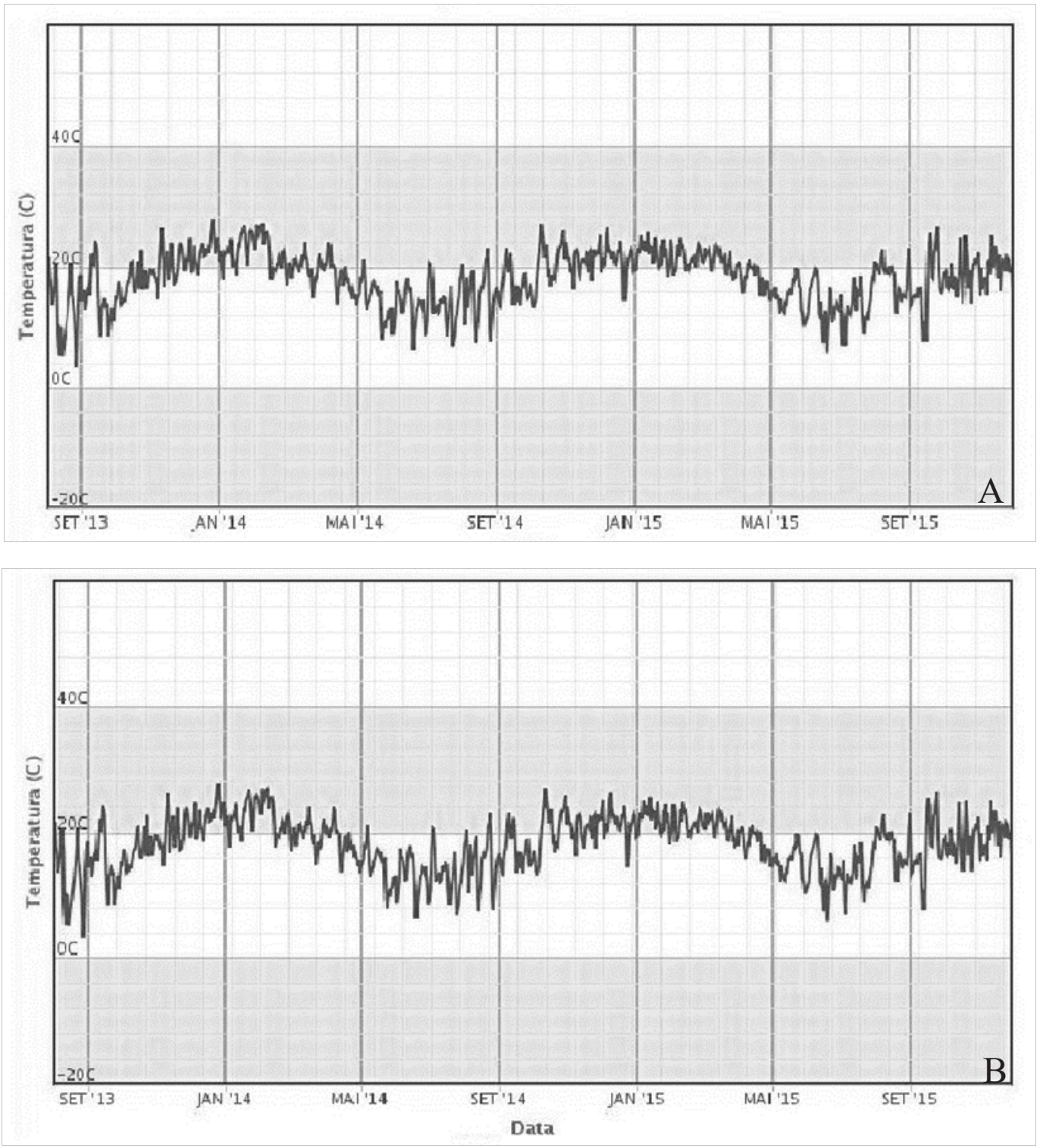

Figura 1. Temperaturas em Lages (A) e Campos Novos (B) (situada a $32 \mathrm{~km}$ do local do experimento em Ibiam) de setembro de 2013 a novembro de 2015. 
Os tratamentos consistiram do plantio de cedroaustraliano em dois locais (Lages e Ibiam) sendo implantados de forma homogênea, mista ou sob o plantio de Pínus taeda com 14 anos. Os tratamentos foram denominados: $\mathrm{T} 1=T$. ciliata (Lages); $\mathrm{T} 2=T$. ciliata + Mimosa scabrella (Lages); T3= T. ciliata + Eucalyptus benthamii (Lages); $\mathrm{T} 4=T$. ciliata (Ibiam) e $\mathrm{T} 5=T$. ciliata sob Pinus taeda (Ibiam). As espécies utilizadas nos consórcios foram escolhidas por serem adaptadas à região e pelo seu rápido crescimento.

Os plantios foram instalados em delineamento de blocos inteiramente ao acaso com quatro repetições. Cada parcela foi constituída por cinco linhas e 10 plantas na linha, totalizando 50 plantas por parcela. O espaçamento utilizado nos plantios puros foi de $3 \mathrm{~m} \times 2 \mathrm{~m}$ sendo $3 \mathrm{~m}$ a distância entre linhas e $2 \mathrm{~m}$ entre plantas na mesma linha. Para os tratamentos intercalados $\operatorname{com} M$. scabrella (bracatinga) e E. benthamii (eucalipto) o plantio foi realizado simultaneamente ao do cedro-autraliano, intercalando-se as linhas de plantio e mantendo-se o mesmo espaçamento do plantio homogêneo.

O plantio realizado no sub-bosque de pínus no Município de Ibiam é adjacente ao local onde foi implantado o cedro-australiano de forma homogênea. O povoamento florestal de pínus foi implantado em 1999, com o espaçamento inicial de $3 \mathrm{~m}$ x $3 \mathrm{~m}$, com 1.111 árvores $\mathrm{ha}^{-1}$, realizando-se desbastes seletivos aos 9 anos e aos 14 anos (agosto de 2013), empregando o índice de espaçamento relativo, tendo restado aproximadamente 500 árvores $\mathrm{ha}^{-1}$. O espaçamento de plantio do cedro-australiano no sub-bosque de pínus foi de $3 \mathrm{~m}$ x $6 \mathrm{~m}$, sendo $3 \mathrm{~m}$ na linha e $6 \mathrm{~m}$ entre linhas. As linhas de plantio foram estabelecidas nas entrelinhas do pínus.

O plantio foi realizado com mudas de origem seminal para todas as espécies. As mudas de cedro-australiano foram adquiridas da Embrapa Florestas, sendo as sementes provenientes de uma área de coleta de sementes (ACS) com 16 anos de idade pertencente à empresa Berneck localizada na cidade de Adrianópolis, PR. As sementes de bracatinga foram oriundas de oito matrizes localizadas na região de Lages, coletadas próximo à Fazenda experimental em que foi realizada a instalação do experimento, sendo as mudas posteriormente produzidas no viveiro florestal da Universidade do Estado de Santa Catarina. As mudas plantadas no experimento tinham em torno de $30 \mathrm{~cm}$ a $40 \mathrm{~cm}$ de altura aos quatro (eucalipto) e cinco (cedro-australiano e bracatinga) meses de idade. As mudas de eucalipto foram adquiridas de viveiro da região.

A área de plantio em Lages foi previamente escarificada, com três dentes, em uma profundidade de $40 \mathrm{~cm}$. Após, foi realizada a aplicação de herbicida glifosato em toda a área $\left(3 \mathrm{~L} \mathrm{ha}^{-1}\right)$.

$\mathrm{Na}$ área de implantação em Ibiam, devido ao relevo acidentado, foram abertas covas manualmente, com aproximadamente $25 \mathrm{~cm}$ de profundidade. No plantio homogêneo, também foi aplicado herbicida glifosato em toda a área $\left(3 \mathrm{~L} \mathrm{ha}^{-1}\right)$. No plantio sob o pínus não foi aplicado herbicida, visto que a área estava sem infestação da matocompetição.

Em ambos os locais o plantio foi realizado em outubro de 2013. Após 20 dias foi realizada a adubação de base com NPK (05 - 20 - 30), aplicando-se 100 g planta $^{-1}$. Trinta dias após o plantio foi realizado o replantio das mudas que apresentaram mortalidade, sendo esse número inferior a 5\% do total. Após a implantação, foi realizada, a cada 6 meses, a roçada nas entrelinhas e coroamento com enxada próximo às mudas, visando a eliminação da matocompetição. Também foi realizada aplicação de formicida de forma sistemática dois meses pré-plantio e, após, feito monitoramento semestral.

Semestralmente após a instalação do experimento foram realizadas as avaliações, sendo mensuradas as seguintes variáveis: sobrevivência (\%); bifurcação (\%) (plantas que apresentaram perda do crescimento primário, originando brotações); altura total da parte aérea (m) e diâmetro do colo (cm). Após o inverno (outubro de 2014 e 2015), aos 12 e 24 meses, foram realizadas avaliações de danos por geadas, utilizando-se uma escala de notas, sendo: 0 - sem dano; 1 - ápices danificados; 2- toda a copa danificada; e 3 - toda a copa e caule danificados. Após a coleta dos dados, estes foram submetidos ao teste de normalidade de Kolmogorov-Smirnov e homogeneidade de variâncias, por meio do teste de Bartlett. Na concordância com estes quesitos, os dados foram submetidos à análise de variância ao nível de $5 \% \mathrm{e}$ $1 \%$ de probabilidade de erro. Quando rejeitada a hipótese h0 (existe diferença significativa entre os tratamentos) aplicou-se o teste de Scott-Knott ao nível de 5\% e 1\% de probabilidade de erro.

\section{Resultados e discussão}

Houve diferença significativa $(p<0,01)$ entre os tratamentos para todas as variáveis avaliadas, mostrando 
diferenças na adaptação e crescimento entre as áreas estudadas. A sobrevivência inicial (aos 6 meses) mostrou-se alta em todos os tratamentos, menor que $12 \%$ (Tabela 1). Estes resultados são similares aos encontrados por Fassio et al. (2009) em plantio de Toona ciliata implantado em Bambuí, MG, em que 95\% das plantas sobreviveram após 60 dias do plantio, evidenciando tolerância ao estresse de plantio. Entretanto, no presente estudo, a avaliação aos 6 meses foi realizada antes do inverno e da ocorrência de geadas na região, fator que seria mais limitante para várias espécies no Sul do Brasil, que o estresse de plantio.

Tabela 1. Médias de sobrevivência, danos por geadas e bifurcação/brotações em Toona ciliata implantado em dois locais de Santa Catarina, Brasil.

\begin{tabular}{|c|c|c|c|c|c|c|c|c|c|c|}
\hline \multirow{3}{*}{$\begin{array}{c}\text { Tratamento } \\
\text { (Local) }\end{array}$} & \multicolumn{4}{|c|}{ Sobrevivência (\%) } & \multicolumn{2}{|c|}{ Dano por geadas } & \multicolumn{4}{|c|}{ Bifurcação/brotação (\%) } \\
\hline & 6 & 12 & 18 & 24 & 12 & 24 & 6 & 12 & 18 & 24 \\
\hline & \multicolumn{4}{|c|}{ Meses } & \multicolumn{2}{|c|}{ Meses } & \multicolumn{4}{|c|}{ Meses } \\
\hline T1 (Lages) & $95 a^{*}$ & $70 \mathrm{~b}$ & $60 \mathrm{~b}$ & $34 \mathrm{~b}$ & $3,0 \mathrm{c}$ & $3,0 \mathrm{c}$ & $0 \mathrm{a}$ & $76 \mathrm{c}$ & $76 \mathrm{c}$ & $92 \mathrm{c}$ \\
\hline T2 (Lages) & $93 a$ & $67 \mathrm{~b}$ & $57 \mathrm{~b}$ & $38 \mathrm{~b}$ & $3,0 \mathrm{c}$ & $3,0 \mathrm{c}$ & $2 \mathrm{a}$ & $80 \mathrm{c}$ & $80 \mathrm{c}$ & $89 \mathrm{c}$ \\
\hline T3 (Lages) & $90 \mathrm{a}$ & $71 \mathrm{~b}$ & $59 \mathrm{~b}$ & $45 \mathrm{~b}$ & $3,0 \mathrm{c}$ & $3,0 \mathrm{c}$ & $4 a$ & $66 \mathrm{c}$ & $66 \mathrm{c}$ & $85 \mathrm{c}$ \\
\hline T4 (Ibiam) & $90 \mathrm{a}$ & $85 \mathrm{a}$ & $79 \mathrm{a}$ & $77 \mathrm{a}$ & $1,2 b$ & $0,7 b$ & $7 a$ & $33 b$ & $35 \mathrm{~b}$ & $40 \mathrm{~b}$ \\
\hline T5 (Ibiam) & $88 \mathrm{a}$ & $87 a$ & $85 \mathrm{a}$ & $85 \mathrm{a}$ & $0,3 \mathrm{a}$ & $0,1 \mathrm{a}$ & $5 \mathrm{a}$ & $11 \mathrm{a}$ & $12 \mathrm{a}$ & $15^{\mathrm{a}}$ \\
\hline
\end{tabular}

Na avaliação aos 12 meses de idade, momento que já houve a ocorrência de geadas, a mortalidade de Toona ciliata (medida como porcentagem de plantas mortas sem presença de brotações na base) elevou-se, atingindo aproximadamente $30 \%$ nos tratamentos implantados em Lages, SC. Nos plantios mistos de cedro-australiano com eucalipto e bracatinga (T2 e T3, respectivamente) foi observada mortalidade similar ao tratamento puro. Isto ocorreu porque o plantio foi efetuado simultaneamente com o eucalipto e a bracatinga, não havendo cobertura.

Nos dois tratamentos implantados em Ibiam, SC a mortalidade foi menor, independente do tratamento (plantio puro ou sob plantio de pínus), principalmente após o primeiro ano da implantação (Tabela 1). Na avaliação aos 18 meses foi observado praticamente o mesmo comportamento dos 12 meses.

Nos dois locais após 24 meses, passados dois invernos após o plantio, a sobrevivência das árvores dos tratamentos sem cobertura diminuiu consideravelmente (T1 a T4), principalmente no plantio em Lages, SC (Tabela 1). No entanto, o plantio realizado sob o pínus apresentou elevada sobrevivência (85\%), mesmo após 24 meses (Tabela 1). Bygrave \& Bygrave (2005) e Dordel et al. (2009) também constataram que a taxa de sobrevivência de T. ciliata foi maior quando plantadas no sub-bosque de Grevillea robusta. Dordel et al. (2009) observaram que o crescimento inicial aumentou com a condição de sub-bosque e a mortalidade aumentou significativamente com a diminuição da densidade do povoamento. Mitchel (1971) observou que os ensaios de cedro-australiano estabelecidos em áreas expostas a geadas, sol e vento mostraram baixa sobrevivência, mas os plantios sob dosséis florestais apresentaram estabelecimento adequado.

O Município de Lages situa-se em uma das áreas mais frias do Brasil, com a ocorrência de fortes geadas (média de 22 ano $\left.^{-1}\right)$. Na região onde está localizado o Município de Ibiam ocorrem geadas menos severas (média de 16 ano $^{-1}$ ) (Aguiar \& Mendonça, 2004). Portanto, considerando os resultados observados (Tabela 1), podese inferir que locais com inverno rigoroso são limitantes ao cultivo do cedro-australiano, como por exemplo na região de Lages, mas a espécie suporta geadas mais brandas. Pinheiro et al. (2006) também afirmam que a espécie sobrevive a temperaturas mínimas absolutas pouco abaixo de $0{ }^{\circ} \mathrm{C}$, podendo suportar até 5 geadas anuais. Entretanto, somente a sobrevivência das plantas não indica se a espécie possui potencial para ser utilizada em determinada região. Para isso, deve-se verificar a adaptação silvicultural, como o crescimento retilíneo e sem bifurcações, forma e estrutura da copa, adaptação às pragas e doenças, além das variáveis volumétricas como altura, diâmetro, fator de forma, entre outros.

Os danos por geadas foram extremos em todos os tratamentos no plantio em Lages. Todas as árvores apresentaram danos na copa e caule nos dois anos de avaliação, causando mortalidade até aproximadamente a região do colo, local onde foi observada a formação de brotações, durante a primavera dos dois anos (Tabela 1). 
Em Ibiam, o tratamento puro apresentou em média danos somente no ápice, em maior grau na avaliação aos 12 meses, diminuindo aos 24 meses. No plantio realizado sob o pínus, os danos observados foram menores, ocorrendo principalmente nos ápices de algumas plantas que foram danificadas. Na avaliação aos 24 meses praticamente não foram observados danos.

Nos dois locais de plantio, os danos provocados pela geada influenciaram diretamente a quebra de dominância apical. No período de avaliação aos 6 meses praticamente não se observou bifurcações, não havendo diferença entre os tratamentos. Após o primeiro inverno, nas avaliações subsequentes, observou-se alta taxa de bifurcação ou múltiplas brotações no plantio realizado em Lages, atingindo 92\% no tratamento puro (Tabela 1).

Ainda em Ibiam, o plantio sob o pínus registrou índice baixo de bifurcação (15\%) após dois anos de plantio (Tabela 1). No plantio puro, a bifurcação atingiu 40\% aos 24 meses, prejudicando sua qualidade silvicultural, devido à perda da dominância. Cusatis (2014) obteve 96,7\% de bifurcação (aos 46 meses) de indivíduos em seleção precoce de Cedrela fissilis para conservação e produção em Floresta Ombrófila Mista. Supõe-se que isso seja uma resposta fisiológica acumulativa de sucessivas geadas. O mesmo estudo também avaliou modelos silviculturais consorciados de $C$. fissilis com P. taeda (49 meses) e, mesmo sob dossel, encontrou um aumento na bifurcação (cedro) após períodos de geadas, diferente do observado nesse trabalho. Desta forma pode-se dizer que o plantio sob dossel é um fator positivo quanto à qualidade silvicultural de T. ciliata .

Em relação à variável altura, não houve diferença entre os tratamentos na avaliação realizada aos 6 meses (altura média $=1,02 \mathrm{~m}$ ). Nos tratamentos instalados em Lages houve diminuição da altura nas avaliações subsequentes (Tabela 2). Essa diminuição se deve à ocorrência de geadas e danos registrados até aproximadamente à região da base, com a formação de brotações novas nesse ponto. Essa situação observada é cíclica, ocorrendo mortalidade da copa e do caule e formação e crescimento das brotações jovens no colo após a ocorrência de geadas (provocando danos). Isso justifica a altura maior nas avaliações realizadas antes do inverno (6 e 18 meses) e menor após o inverno (12 e 24 meses).
Tabela 2. Médias de altura e diâmetro do colo (DAC) em Toona ciliata implantado em dois locais de Santa Catarina, Brasil.

\begin{tabular}{ccccccccc}
\hline \multirow{2}{*}{$\begin{array}{c}\text { Tratamento } \\
\text { (Local) }\end{array}$} & \multicolumn{4}{c}{$\begin{array}{c}\text { Altura (m) } \\
\text { Meses }\end{array}$} & \multicolumn{4}{c}{ DAC (cm) } \\
\cline { 6 - 10 } & $\mathbf{6}$ & $\mathbf{1 2}$ & $\mathbf{1 8}$ & $\mathbf{2 4}$ & $\mathbf{6}$ & $\mathbf{1 2}$ & $\mathbf{1 8}$ & $\mathbf{2 4}$ \\
\hline T1 (Lages) & $1,10 \mathrm{a}^{*}$ & $0,46 \mathrm{c}$ & $0,80 \mathrm{~b}$ & $0,33 \mathrm{c}$ & $1,47 \mathrm{a}$ & $1,71 \mathrm{a}$ & $2,09 \mathrm{a}$ & $2,31 \mathrm{~b}$ \\
T2 (Lages) & $0,99 \mathrm{a}$ & $0,41 \mathrm{c}$ & $0,79 \mathrm{~b}$ & $0,36 \mathrm{c}$ & $1,44 \mathrm{a}$ & $1,67 \mathrm{a}$ & $2,05 \mathrm{a}$ & $2,47 \mathrm{~b}$ \\
T3 (Lages) & $1,05 \mathrm{a}$ & $0,65 \mathrm{~b}$ & $0,87 \mathrm{~b}$ & $0,46 \mathrm{c}$ & $1,49 \mathrm{a}$ & $1,60 \mathrm{a}$ & $1,96 \mathrm{a}$ & $2,35 \mathrm{~b}$ \\
T4 (Ibiam) & $0,98 \mathrm{a}$ & $1,40 \mathrm{a}$ & $1,93 \mathrm{a}$ & $2,58 \mathrm{a}$ & $1,53 \mathrm{a}$ & $1,84 \mathrm{a}$ & $2,35 \mathrm{a}$ & $3,10 \mathrm{a}$ \\
T5 (Ibiam) & $0,96 \mathrm{a}$ & $1,46 \mathrm{a}$ & $1,64 \mathrm{a}$ & $1,85 \mathrm{~b}$ & $1,42 \mathrm{a}$ & $1,51 \mathrm{a}$ & $1,72 \mathrm{a}$ & $1,94 \mathrm{~b}$ \\
\hline
\end{tabular}

*Médias seguidas por letras iguais não diferem entre si na coluna pelo teste de Scott-Knott a 1\% de probabilidade.

Como os danos pela geada foram menores em Ibiam (T4 e T5), as plantas apresentaram crescimento constante ao longo das avaliações. Após dois anos da implantação, o tratamento puro atingiu maior altura $(2,58 \mathrm{~m}) \mathrm{em}$ comparação ao plantio sob o pínus $(1,85 \mathrm{~m})$ (Tabela 2$)$.

O menor crescimento do cedro-australiano sob o pínus é justificado pelo sombreamento, pois a floresta com pínus causa baixa abertura de luz, podendo prejudicar o crescimento, apesar de proteger as mudas dos efeitos da geada. Segundo Strand et al. (2006), o crescimento das plantas sob cobertura é afetado, entre outros fatores, pelas condições de luminosidade, umidade e disponibilidade de nutrientes no solo. Bygrave \& Bygrave (2005), no estudo sobre o sucesso de plantações de T. ciliata e Cedrela sp. na Austrália, afirmam que o cedro-australiano em áreas abertas apresentou rápido crescimento em altura e diâmetro, atingindo alturas superiores a $10 \mathrm{~m}$ em 18 meses. As mudas plantadas no sub-bosque de espécies de eucalipto obtiveram maior crescimento em altura, porém um menor incremento em diâmetro.

No nordeste da Argentina, o crescimento de T. ciliata em altura e diâmetro foram maiores em plantios sob dossel de G. robusta do que sob espécies de pínus (Dordel et al., 2009). Os autores justificaram os resultados devido à maior competição entre plantas quando sob pínus. Os autores concluíram ainda que a taxa de crescimento de T. ciliata aumenta com a diminuição da densidade de $P$. taeda, sendo que essa tendência não foi observada no plantio de $G$. robusta com $P$. elliottii x P. caribea. Dobner Junior et al. (2009) também encontraram efeito positivo na cobertura de E. dunnii plantado sob P. taeda. 
O aumento da intensidade de cobertura, até 50 árvores ha $^{-1}$ de $P$. taeda, diminuiu os danos causados por geadas com temperaturas de até $-5{ }^{\circ} \mathrm{C}$ e aumentou a resiliência das plantas afetadas.

A presença da cobertura arbórea sobre outras espécies pode auxiliar na tolerância das plantas a temperaturas iguais ou inferiores a $0{ }^{\circ} \mathrm{C}$ e a geadas, da mesma forma que noites nubladas diminuem a perda de calor por radiação da superfície da Terra para a atmosfera (Dobner Junior et al., 2009). O microclima dentro de uma área florestal é diferente de uma área aberta. A amplitude de variação térmica próxima ao solo é mais alta em áreas abertas, com maior duração da incidência de luz solar e temperaturas noturnas mais baixas (Langvall \& Löfvenius, 2002).

O cedro-australiano tem a vantagem de ser uma espécie que tolera sombra nos estágios iniciais, não comprometendo a sobrevivência e diminuindo os efeitos de restrição do crescimento em altura e diâmetro. Espécies intolerantes à sombra tendem a ter taxas de crescimento comprometidas em tais situações, o que pode prejudicar a adoção de plantio sob dossel ou plantios mistos (Strand et al., 2006).

Apesar do efeito negativo da geada, principalmente nos tratamentos de Lages, o diâmetro do colo (DAC) aumentou ao longo dos anos de avaliações (Tabela 2). O maior DAC foi encontrado no tratamento puro instalado em Ibiam e o menor no mesmo local, sob o pínus. Os resultados confirmam que apesar da cultura suportar o sombreamento, seu crescimento é menor em plantios sombreados, principalmente sob dossel de pínus.

\section{Conclusões}

O cedro-australiano não deve ser recomendado para o plantio em regiões muito frias, com grande ocorrência de geadas, como no caso da região de Lages, SC. Entretanto, em locais com frio de menor intensidade (e menor ocorrência de geadas), como no caso da região de Ibiam, SC, a espécie apresenta potencial para plantios. Novos plantios experimentais devem ser instalados para melhorar o conhecimento da adaptação e características silviculturais da espécie, sendo interessante o investimento em plantios sombreados. Neste sentido devem ser estudadas outras espécies, especialmente com características de rápido crescimento, para serem usadas como cobertura florestal no plantio de Toona ciliata.

\section{Referências}

Aguiar, D. \& Mendonça, M. Climatologia das geadas em Santa Catarina. In: SIMPÓSIO BRASILEIRO DE DESASTRES NATURAIS, 1., 2004, Florianópolis. Anais... Florianópolis: GEDN/ UFSC, 2004. p. 762-773. CD-ROM.

Ares, A. \& Fownes, J. H. Productivity, nutrient, and water-use efficiency of Eucalyptus saligna and Toona ciliata in Hawaii. Forest Ecology and Management, n. 139, p. 227-236, 2000. DOI: 10.1016/ S0378-1127(00)00270-X.

Berri, P. V. Incremento de Pínus elliottii em diferentes pesos de desbaste e desenvolvimento inicial de Araucaria angustifolia, Ibiam, SC. 2015. 74 p. Dissertação (Mestrado em Engenharia Florestal) - Universidade do Estado de Santa Catarina, Lages.

Bristow, M. et al. Growing rainforest timber trees: a farm forestry manual for north Queensland. Barton: Rirdc, 2005. 77 p. (Publication, 03/010)

Bygrave, F. L. \& Bygrave, P. L. Growing Australian red cedar: and other Meliaceae species in plantation. Canberra: Rural Industries Research and Development Corporation, 2005. 84 p. Disponível em: $<$ https://rirdc.infoservices.com.au/downloads/04-135.pdf $>$. Acesso em: 3 fev. 2014.

Castro-Gamboa, I. Estudo fitoquímico da raiz de Toona ciliata e do cavalo do enxerto de Toona ciliata/Cedrela odorata: uma contribuição à quimiossistemática e à ecologia na interação Hypsipyla-Meliaceae. 2000. 212 f. Tese (Doutorado em Química) Universidade Federal de São Carlos, São Carlos.

Cunningham, S. A. et al. Patterns of host use by the shoot-borer Hypsipyla robusta (Pyralidae: Lepidoptera) comparing five Meliaceae tree species in Asia and Australia. Forest Ecology and Management, v. 295, n. 1-3, p. 351-357, 2005. DOI: 10.1016/j. foreco.2004.10.042.

Cusatis, A. C. Melhoramento genético e silvicultural de Cedrela fissilis Vell. e Pínus taeda L.. 2014. 168 f. Tese (Doutorado em Engenharia Florestal) - Universidade Federal do Paraná, Curitiba.

Dobner Junior, M. et al. Efeito da cobertura de Pínus taeda L. na proteção contra geadas e no crescimento de plantas jovens de Eucalyptus dunnii Maiden. Floresta, v. 39, n. 4, p. 807-823, 2009. DOI: $10.5380 /$ rf.v39i4.16315 .

Dordel, J. et al. Trade-offs among establishment success, stem morphology and productivity of underplanted Toona ciliata: effects of nurse-species and thinning density. Forest Ecology and Management, v. 259. v. 9, p. 1846-1855, 2009. DOI: 10.1016/j. foreco.2009.05.040.

Fassio, P. O. et al. Sistema agrossilvipastoril com cedro-australiano para fomento na região de Bambuí: Estudos Preliminares. In: SEMANA DE CIÊNCIA E TECNOLOGIA DO IFMG DO CAMPUS BAMBUÍ, 2., 2009, Bambuí. [Anais eletrônicos]. Bambuí: Instituto Federal de Minas Gerais, 2009. Disponível <http://www.cefetbambui. edu.br/sct/trabalhos/Recursos\%20Naturais/162-PT-10.pdf $>$. Acesso em: 7 jan. 2016.

Holdridge, L. R. \& Poveda, L. J. Arboles de Costa Rica. San José, Costa Rica: Centro Cientifico Tropical, 1975. 374 p.

Pesq. flor. bras., Colombo, v. 37, n. 89, p. 47-54, jan./mar. 2017 
Langvall, O. \& Löfvenius, M. O. Effect of shelterwood density on nocturnal near-ground temperature, frost injury risk and budburst date of Norway spruce. Forest Ecology and Management, v. 168, p. 149-161, 2002. DOI: 10.1016/S0378-1127(01)00754-X.

Lorenzi, H. et al. Árvores exóticas no Brasil: madeireiras, ornamentais e aromáticas. Nova Odessa: Instituto Plantarum, 2003. $384 \mathrm{p}$.

Mitchell, A. L. Planting trials with Red Cedar. Australian Forestry, v. 35, n. 1, p. 8-16, 1971.

Nisgoski, S. et al. Anatomia da madeira de Toona ciliata características das fibras para produção de papel. Floresta, v. 41, n. 4, p. 717-728, 2011. DOI: /10.5380/rf.v41i4.25337.

Paludzyszyn Filho, E. et al. Eucaliptos indicados para plantio no Estado do Paraná. Colombo: Embrapa Florestas, 2006. 45 p. (Embrapa Florestas. Documentos, 129).

Pinheiro, A. L. et al. Cedro australiano: cultivo e utilização (Toona ciliata M. Roem. Var. australis (F. Muell) Bahadur). Viçosa, MG: Ed. da UFV, 2006. 42 p.
Souza, J. C. A. V. de. et al. Cedro-australiano (Toona ciliata). Niterói: Secretaria de Estado de Agricultura, Pecuária, Pesca e Abastecimento, 2010. 14 p. (Programa Rio Rural. Manual técnico, 21).

Souza, J. C. A. V. Propagação vegetativa de Cedro-australiano (Toona ciliata M. Roemer) por miniestaquia. 41 p. Dissertação (Mestrado em Produção Vegetal), Universidade Estadual do Norte Fluminense, Campos dos Goytacazes, 2007.

Strand, M. et al. Height growth of planted conifer seedlings in relation to solar radiation and position in scots pine shelterwood. Forest Ecology and Management, v. 224, p. 258-265, 2006. DOI: 10.1016/j.foreco.2005.12.038.

Trianoski, R. et al. Propriedades físicas, químicas e mecânicas da madeira de cedro australiano cultivado em Corupá, SC. Pesquisa Florestal Brasileira, v. 34, n. 80, p. 435-441, 2014. DOI: 10.4336/2014.pfb.34.80.523.

Zoneamento ecológico para plantios florestais no Estado de Santa Catarina. Curitiba: EMBRAPA-CNPF, 1988. 113 p. (EMBRAPACNPF. Documentos, 21). 